\title{
Improving participatory resilience assessment by cross-fertilizing the Resilience Alliance and Transition Movement approaches
}

\author{
My M. Sellberg ${ }^{1}$, Sara T. Borgström $^{1,2}$, Albert V. Norström $^{1}$ and Garry D. Peterson $^{1}$
}

\begin{abstract}
The concept of resilience is currently being widely promoted and applied by environmental and development organizations. However, their application of resilience often lacks theoretical backing and evaluation. This paper presents a novel cross-fertilization of two commonly used approaches for applying resilience thinking: the grassroots movement of Transition Towns and the Resilience Alliance's Resilience Assessment. We compared these approaches through a text analysis of their key handbooks and combined them in a series of participatory workshops with a local partner active in the Transition Movement. Our results demonstrate that despite sharing a number of key features, these two approaches have complementary strengths and weaknesses. Strengths of the Transition Movement include its motivating overarching narrative of the need to transform in response to global sustainability challenges, as well as practical tools promoting learning and participation. The Resilience Assessment's conceptual framework and structured process generated context-specific understanding of resilience, but provided little guidance on navigating transformation processes. Combining the Resilience Assessment's theory on complex systems with the Transition Movement's methods for learning also generated synergies in fostering complexity thinking. Based on these findings, we believe that integrating strengths from both approaches could be widely useful for practitioners seeking to apply resilience for sustainable development. Our study also highlights that methods for assessing resilience can be improved by combining insights from science and practice.
\end{abstract}

Key Words: sustainability science; sustainable development; transdisciplinary research; transformation; Transition Towns

\section{INTRODUCTION}

Resilience of social-ecological systems is one of the core research interests of sustainability science (Kates et al. 2001). Interest in resilience has grown dramatically over the past decade (Xu and Marinova 2013, Baggio et al. 2015), which has led to an increasing demand for methods to apply resilience thinking. One of the bestdocumented approaches is described in The Resilience Assessment Workbook (Resilience Alliance 2010). This is based on a strong foundation of theory and empirical research on social-ecological systems, from a complex adaptive systems perspective (Quinlan et al. 2015). On the other hand, different civil society movements are also applying resilience thinking, such as the Transition Movement, which promotes transformative societal change in response to contemporary sustainability challenges (Hopkins 2009). The Resilience Assessment process is the most developed scientifically based approach to applying resilience thinking, whereas the Transition Movement represents one of the largest communities of practice working with resilience thinking. We present a novel comparison of these two approaches that analyzes how they can cross-fertilize to improve the application of resilience thinking in participatory processes.

The Transition Movement and the Resilience Assessment represent two different approaches to using resilience thinking with potentially complementary strengths. Previously, scholars applying Resilience Assessment in practice have found that it fails to provide guidance on how to manage the participatory learning process (Mitchell et al. 2014, Sellberg et al. 2015). Furthermore, although resilience scholars often emphasize transformational change for sustainable development (Gunderson and Holling 2002, Folke et al. 2010, Olsson et al. 2014), the practice of Resilience Assessment as of yet has failed to support transformations of social-ecological systems (Walkerden et al. 2013, Sellberg et al. 2015). Earlier work has addressed these issues by combining Resilience Assessment with ideas from adaptive management and collective learning (Walkerden et al. 2013, Mitchell et al. 2014). However, no one so far has engaged with the Transition Movement, even though it focuses on mobilizing citizens in collective learning processes for transition (Hopkins 2011). Haxeltine and Seyfang (2009:20) provided an initial comparison between literature on social-ecological resilience (e.g., Folke 2006) and the Transition Movement and found that the movement has been successful in using resilience as a framing concept, but that there is a lack of a deeper understanding of what building resilience means for each specific context, as well as "an adequate conceptual and operational framework for resilience." Within the movement, there is also an interest in analyzing resilience and assessing the impact of initiatives (Hopkins 2011). This suggests that the Resilience Assessment approach also could be useful for the Transition Movement.

In this paper, we compare and combine the Resilience Assessment and the Transition Movement approaches, with an aim to generate insights for the application of resilience thinking in participatory settings. Specifically, we (1) compared the notions of resilience as presented in the handbooks of the two approaches (Hopkins 2008, 2011, Resilience Alliance 2010) through a qualitative text analysis and (2) developed a new participatory workshop protocol influenced by the two approaches, in collaboration with local partners active in the Transition Movement in Southern Sweden, and assessed the benefits and challenges of that cross-fertilization process. To our knowledge, this is the first time the Resilience Assessment and Transition Movement approaches have been compared and combined in a scientific study. 


\section{BACKGROUND}

\section{The Resilience Assessment}

The Resilience Assessment Workbook was developed by the Resilience Alliance research network (2010) and was originally aimed at the practical management of regional ecosystems. The current process includes describing a social-ecological system, assessing its resilience, and finding options for interventions. The aim is to generate an understanding of the dynamics and aspects of resilience in a system, rather than measuring resilience (Walker and Salt 2012). The approach has a strong theoretical foundation and builds on earlier work by the Resilience Alliance to apply resilience thinking (Walker et al. 2002), as well as recent insights from case studies of social-ecological systems (Quinlan et al. 2015). The latest version of The Resilience Assessment Workbook for Practitioners has been applied across the world (Resilience Alliance 2016) and in different contexts (e.g., Haider et al. 2012, Liu 2014, Sellberg et al. 2015), but most extensively in Australia by regional water catchment management authorities (e.g., Walker et al. 2009, Mitchell et al. 2014). In this way, the approach of the Resilience Alliance (2010) is more flexible compared with other recent approaches that are tailored to specific contexts (Quinlan et al. 2015), such as social-ecological production landscapes and seascapes (UNU-IAS, Bioversity International, IGES, and UNDP 2014).

\section{The Transition Movement}

The Transition Movement, also called the Transition Towns movement, emerged in 2005 in the United Kingdom, and its rapid spread has caught the attention of a growing number of researchers, relating it to grassroots innovations (Seyfang and Haxeltine 2012, Feola and Nunes 2014), community development (Connors and McDonald 2011), and social movements (Smith 2011), among others. In 2016, the movement included well over 1000 initiatives across the world (Transition Network 2016). Rob Hopkins is the movement's front figure and has written two handbooks, with support from the Transition Network:The Transition Handbook (Hopkins 2008) and The Transition Companion (Hopkins 2011). The Transition Handbook has sold more than 25,000 copies in the United Kingdom alone (Transition Culture 2017). The purpose of the handbooks is to inspire citizens around the world to join the movement, and to guide local transition initiatives to be successful. Resilience is a key concept in the Transition Movement, with a specific focus on building resilience of local communities to peak oil, climate change, and economic crisis (Hopkins 2008, 2011). As opposed to other approaches to applying resilience (e.g., Rockefeller Foundation 2013), the movement is strongly influenced by the Resilience Alliance's definition of resilience (e.g., Walker et al. 2004, Walker and Salt 2006, as cited in Hopkins 2008). Nevertheless, with the exception of Haxeltine and Seyfang (2009) and Brunetta and Baglione (2013), few studies relate the Transition Movement to theory on social-ecological resilience.

\section{METHODS}

Both the Resilience Assessment and the Transition Movement are characterized by a high level of interplay between written guidelines and practical applications in different contexts. Therefore, we applied two different methodological approaches: a qualitative text analysis of their written guidelines and a participatory case study (Fig. 1). The comparison of their written guidelines allowed for a general comparison that highlights differences and commonalities between the Transition Movement and the Resilience Assessment. By complementing this analysis with a practical case study embedded in a specific region, we captured some of the discrepancies between theory and practice. Below, we describe the two methods further.

Fig. 1. Methodological approach. This study is based on two methodological approaches: Through a qualitative text analysis we compared the written guidelines of the Resilience Assessment and the Transition Movement (comparing written guidelines through qualitative text analysis), and by combining the two approaches in a case study with a partner organization, we explored benefits and challenges of cross-fertilizing the approaches (combining the approaches in a practical case).

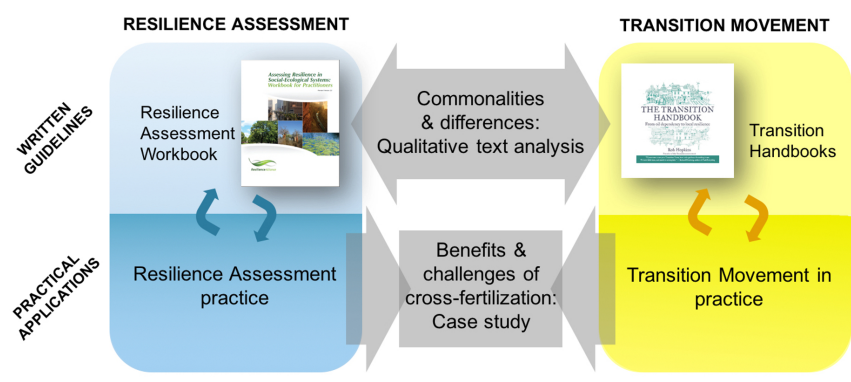

Comparing written guidelines through qualitative text analysis The material we selected included The Transition Handbook (Hopkins 2008), The Transition Companion (Hopkins 2011), and The Resilience Assessment Workbook for Practitioners (Resilience Alliance 2010). These are the most widely used written guidelines for the respective approaches. Hopkins (2011) accounts for some of the conceptual and practical changes in the movement since Hopkins (2008).

Following Esaiasson et al. (2007), we developed a framework to structure the comparison (Table 1). The framework included a brief narrative analysis based on the approach of Leach et al. (2010), which helped provide a context for the rest of the findings (1. Narrative); the interpretation of resilience, using, e.g., Biggs et al.'s (2015) resilience principles and Folke et al.'s (2010) resilience thinking framework (2. Definition and use of resilience concept); and conceptualizations of social-ecological and crossscale interactions, and the types of activities advocated (3. Emphasis on theory vs. practical tools). The last category was based on preliminary case study findings, which indicated that the Transition Movement approach focused more on practical tools, whereas the Resilience Assessment had a stronger theoretical foundation. This notion also aligned with another recent study of a resilience assessment process (Sellberg et al. 2015). In order not to miss interesting findings, we also included interpretations of resilience in practice that emerged from the text analysis (2E in Table 1). A more detailed description of the analysis and framework is provided in Appendix 1.

\section{Combining the approaches in a practical case}

In the case study, we cross-fertilized the Transition Movement and Resilience Assessment approaches through developing and 
Table 1. Framework for the qualitative text analysis comparing handbooks of the Transition Movement approach (Hopkins 2008, 2011) and the Resilience Assessment approach (Resilience Alliance 2010). Numbers and letters refer to the categories in Appendix 1; text analysis results.

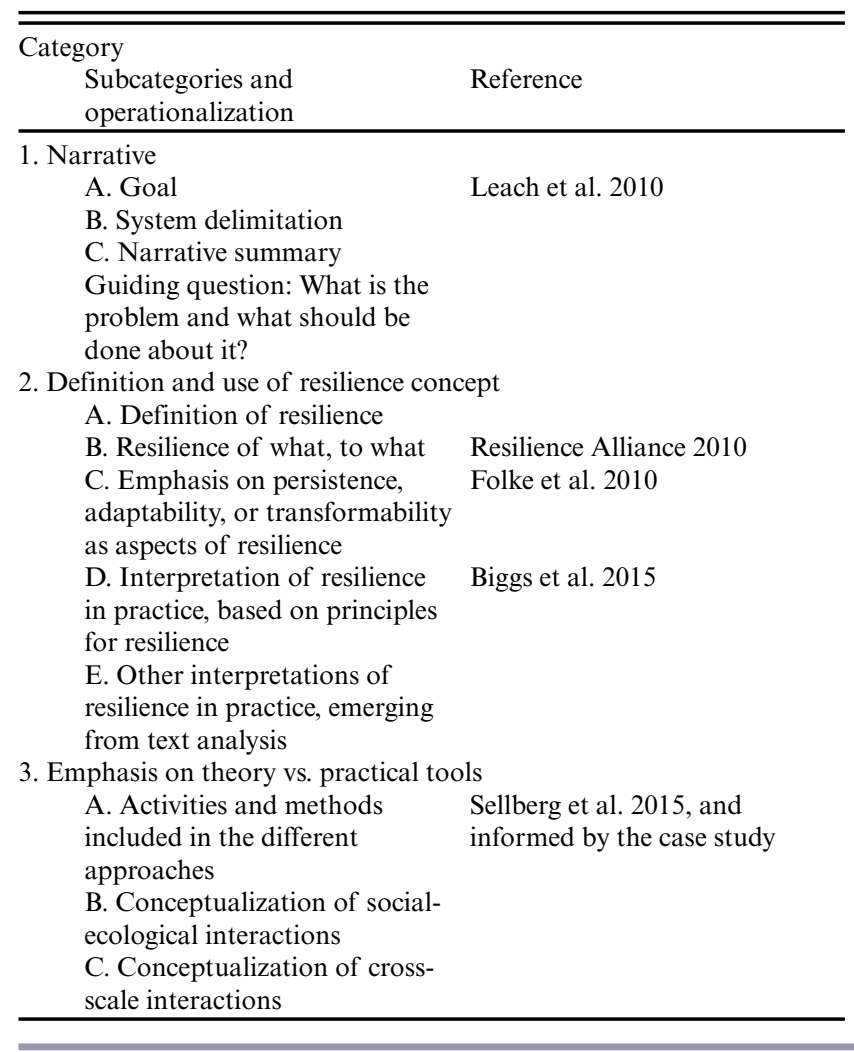

testing a new workshop protocol that combined the two approaches, and then evaluated the benefits and challenges of that cross-fertilization process.

The case study was conducted in Southern Sweden in collaboration with a LEADER organization (Fig. 2). LEADER is the EU's rural development program and aims to strengthen locally driven development within defined rural areas (European Commission 2016). The organization was already influenced by the Transition Movement approach, e.g., through their involvement in a broader project called "LEADER learns for transition to sustainability." In 2013, two project coordinators at the organization contacted us, because they were interested in learning more about resilience thinking as an important part of the Transition Movement approach and using Resilience Assessment as a tool for participatory strategic planning. Both of them had personal experience of the Transition Movement: one of them in a local transition initiative and the other through starting up and working with education in the national Transition Movement in Sweden.

Inspired by the transdisciplinary research process of Lang et al. (2012), we formed a team of researchers and practitioners who framed the research task, created a one-day workshop that we conducted in three different local communities between January and April 2014 (more details in Appendix 2), and attempted to integrate the outcomes in our respective practices. The goals of the workshop were to perform the first steps of the Resilience Assessment; contribute with a new perspective to the ongoing local planning processes that took place in two of the localities; and to contribute to learning, both for the participants regarding resilience thinking and for us through method development. The workshop agenda included (1) deciding what needs to be resilient and what is threatening those values, (2) identifying strengths and weaknesses related to the threats, and (3) mapping strategies to increase resilience. Apart from the workshop protocol, we also coproduced a list of characteristics of resilient systems, which we used during the last part of the workshop (Appendix 3). Thresholds of potential concern were not assessed, because that would have required a longer learning process. The workshop participants (72 in total) were people engaged in their local community and/or in environmental issues, including representatives from civil society and local authorities, which is similar to the Transition Movement's activities in different parts of the world.

Fig. 2. Map of the case study area in Southern Sweden. The LEADER region where the collaboration project took place included four municipalities: Eksjö, Hultsfred, Oskarshamn, and Vimmerby. The region is largely rural and the biggest town has 17,000 inhabitants (SCB 2010). The landscape consists of a mix of forests and agricultural land, interspersed with several smaller lakes.

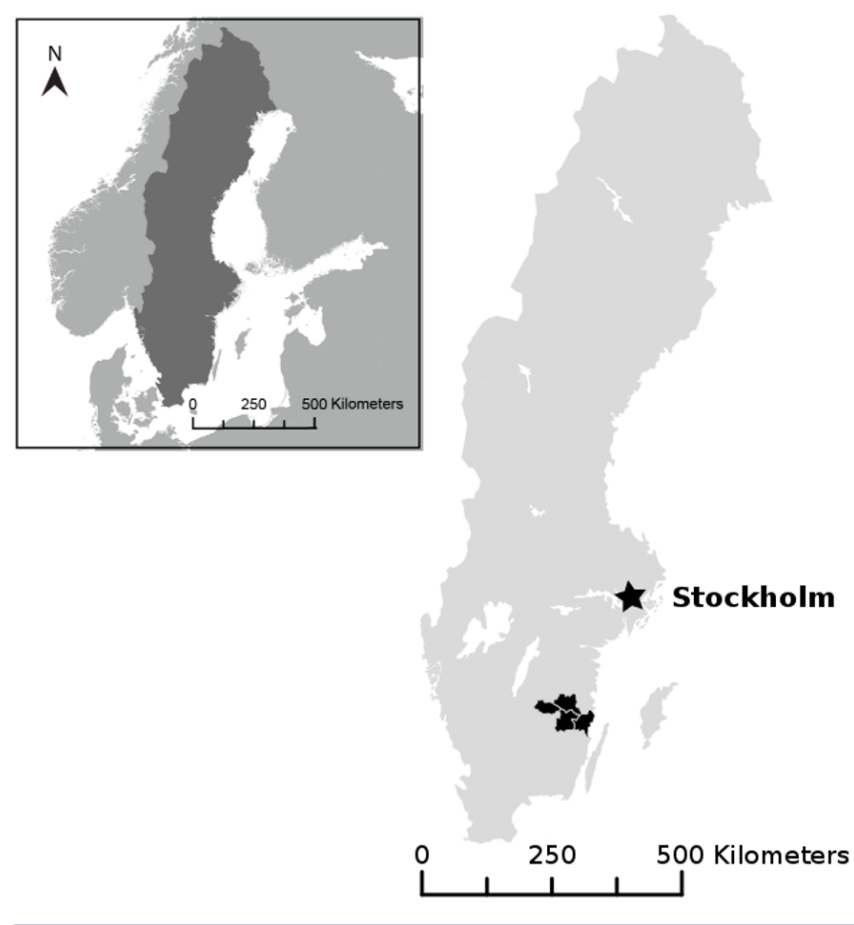

To document the process, we wrote field notes (Jorgensen 1989) and conducted semistructured interviews (Kvale and Brinkmann 2009). We interviewed the two collaborators from the LEADER organization, hereby referred to as the partners (partner $1=\mathrm{P} 1$ and partner $2=\mathrm{P} 2$ ), both before and after the workshops to capture their expectations and aspirations, as well as their 
reflections of what they had learned and what the challenges had been (Appendix 4). The interviews, as well as the reflection rounds in the end of each workshop, were recorded and transcribed. Field notes were written after each meeting with the partners and included memos of preliminary interpretations of the data (Glaser 1998, Charmaz 2006). To analyze the case study data, we used an inductive approach influenced by grounded theory (Charmaz 2006, Wagenaar 2011). We analyzed transcripts from the interviews and reflection rounds at the workshops, field notes, and material from the workshops, such as invitations and agendas, using the software Atlas.ti (Friese 2012). The codes were developed iteratively and were framed by our research question to identify benefits and challenges of cross-fertilization (Table 2, Appendix 5).

Table 2. List of focused codes from the inductive analysis of the case study data. See descriptions of each code in Appendix 5.

\begin{tabular}{ll}
\hline \hline Category & Focused codes \\
\hline $\begin{array}{l}\text { Reflections on commonalities and } \\
\text { differences }\end{array}$ & 1. Finding common ground \\
& 2. Acknowledging the different \\
& roles of research and movement \\
Benefits of cross-fertilization: & 3. Operationalizing resilience \\
contributions of the & 4. Reaching new groups \\
Resilience Assessment approach & 5. Bridging divide/bypassing clinch \\
& 6. Reframing sustainability \\
& 7. Including local and global issues \\
& 8. Highlighting strengths \\
& 9. Using new concept \\
& 10. Problematizing global economy \\
& 11. Using pedagogical exercises \\
Benefits of cross-fertilization: & 12. Acknowledging emotions \\
contributions of the & 13. Promoting transition \\
Transition Movement approach & 14. Defining "of what" \\
& 15. The pedagogical task \\
Challenges of cross-fertilization & 16. The learning process \\
and of & 17. Openness in participatory \\
applying resilience & 18. Losing the ecological \\
& dimension? \\
\hline &
\end{tabular}

\section{RESULTS}

Here we present the key commonalities and differences derived from the written guidelines of the Transition Movement and the Resilience Assessment (Fig. 3, detailed table in Appendix 1). We also describe the main benefits and challenges of combining the approaches, synthesized from the case study analysis (Appendix $5)$.

\section{Key commonalities}

Both approaches emphasize the need to build resilience in their narratives, and share an overarching goal of sustainability (Fig. 3, Appendix 1:1). For example, the work of Hopkins (2011) is based on values of global environmental sustainability, human well-being, and social justice, and Resilience Alliance (2010:4) is concerned with achieving a "sustainable long-term delivery of environmental benefits linked to human well-being."
Fig. 3. Key commonalities and differences. Derived from a qualitative text analysis between the Resilience Assessment's and the Transition Movement's respective written guidelines. See detailed table in Appendix 1.

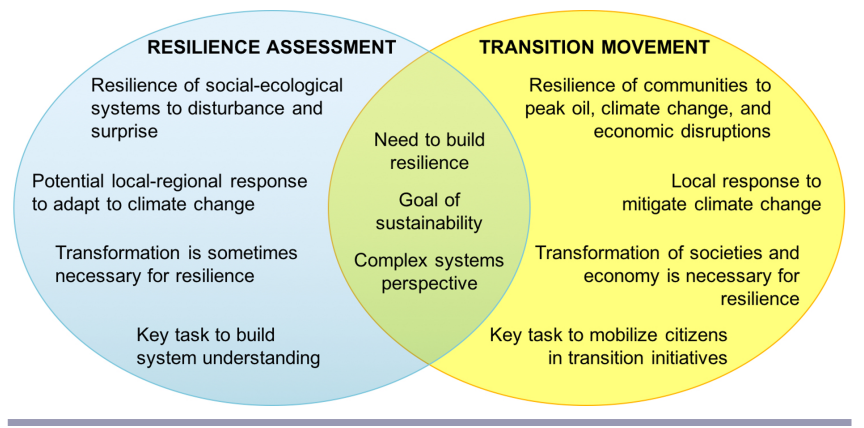

The approaches also share a complex adaptive systems perspective (Fig. 3, Appendix 1:2D4). The concept of complex adaptive systems is a key component of resilience thinking (Walker and Salt 2006): the underlying theoretical framework of the Resilience Assessment approach. Similarly, resilience thinking and the idea of self-organizing systems influence the Transition Movement approach (Hopkins 2011). However, Resilience Assessment includes more concepts related to complex adaptive systems and dynamic systems, such as alternative system regimes with thresholds (Resilience Alliance 2010) and the adaptive cycle and panarchy (Resilience Alliance 2010).

\section{Key differences}

The Transition Movement handbooks promote building community resilience (e.g., Hopkins 2008), while the Resilience Alliance (2010) promotes building resilience of social-ecological systems delivering important ecosystem services (Fig. 3). To define system boundaries, the Transition Movement approach is guided by citizens' perceived sphere of influence (Hopkins 2008, 2011), whereas Resilience Assessment uses key natural resource management issues (Resilience Alliance 2010). Nevertheless, Hopkins (2011:44) is also concerned that a community's resource base should be "resilient and accessible." This indicates that both approaches have a social-ecological perspective, but with different starting points: the community versus the landscape and its natural resources.

The Transition Movement guides the choice of focus issues, whereas Resilience Assessment leaves it open initially (Fig. 3). The Resilience Assessment approach is framed around natural resource management and increasing environmental change caused by human activities (Appendix 1:1C), but apart from that, key issues and disturbances ("resilience to what") are open to be decided at the outset of each assessment (Resilience Alliance 2010). Any indicators of resilience will be context dependent and not predefined. The Transition Movement approach, on the other hand, guides local initiatives to build resilience to peak oil and economic contractions, as well as to mitigate the effects of climate change (Hopkins 2011). A key strategy is then for a community to reduce its dependence on cheap energy and fossil fuels, reflected in the proposed resilience indicators of Hopkins (2008). However, the approach is also about local responses to mitigate climate 
change, following the slogan "think globally, act locally" (Hopkins 2011:280). The Resilience Alliance (2010) focuses on the resilience of a local-regional focal system and does not ask questions about how that system could affect the global scale on an aggregate level. It could more easily be used for climate adaptation than for climate mitigation, shown by the examples of flooding in New Orleans and forest fires.

The two approaches put different emphasis on transformability as an aspect of resilience (Fig. 3). Transformability is the ability "to create a fundamentally new system when ecological, economic, or social structures make the existing system untenable" (Folke et al. 2010:3). The Resilience Assessment describes transformation as an option if existing structures become untenable (Resilience Alliance 2010). Both examples in The Resilience Assessment Workbook are transformations to more adaptive and ecosystem-based governance and management: Kristianstad and the Great Barrier Reef. The Transition Movement describes transformation as necessary for becoming resilient (Appendix 1:1C). Resilience is seen as "more than 'sustaining current models and practices"" but rather "a rethink of assumptions about infrastructure and systems that should lead to a more sustainable, resilient and enriching low-carbon economy" (Hopkins 2011:45). When Hopkins (2011) envisions the future of food, energy, and housing, he writes about a revolution or transformation of the current system.

Even if sharing an overarching sustainability goal, the approaches have different purposes and promote different activities (Fig. 3). The Transition Movement intends to mobilize citizens in local transition initiatives; therefore, broadening participation and encouraging learning are key strategies (Appendix 1:2D5-6). It suggests a number of activities for engaging people, building social networks, and raising awareness (Appendix 1:3A), and Hopkins (2011) includes a range of practical tips on how to, e.g., speak in public or run effective meetings. In contrast, the purpose of the Resilience Assessment is foremost to generate system understanding to improve natural resource governance. Resilience Alliance (2010) applies the theoretical framework of resilience thinking to develop conceptual diagrams and a synthesized understanding of the system, which serves as a basis for decision making and adaptive management.

\section{Benefits of cross-fertilization}

We synthesized the case study results of cross-fertilizing the Transition Movement and Resilience Assessment approaches into the following four categories of benefits.

\section{Communicating and applying resilience}

Through the collaboration project, the partners learned to apply and communicate resilience: “...Now I've got both words, tools and examples that allow me to communicate to others..." (P1; Appendix 5:3). The Resilience Assessment approach contributed to this in three main ways. First, we used its overall structure, which begins by deciding what should be resilient and to what type of disturbances ("resilience of what, to what," sections 1.2 and 1.3 in Resilience Alliance 2010), to design the workshop agenda (Appendix 2). Second, the resilience characteristics (Appendix 3), e.g., modularity and diversity, were useful to communicate resilience to the workshop participants and explore strengths and weaknesses of their communities. Third, we also communicated the idea of complex systems in presentations and exercises during the workshops. One of the partners said afterward that "to understand resilience, you need to understand complex systems" (P1) and saw the workshop as potentially useful to foster an understanding of resilience and complex systems more broadly within the Transition Movement (Appendix 5:1).

\section{Linking across scales and world views}

The partners saw the Resilience Assessment approach as a way to overcome difficulties in reaching ordinary people in the countryside with a global sustainability perspective (Appendix 5:4), as well as to bridge the present divide between sustainability and rural development in their own organization (Appendix 5:5). Compared with the Transition Movement approach, which one of them described as being "more about transitioning for the sake of the climate, that is a lot for someone else's sake, for your children and grandchildren's sake," the Resilience Assessment approach enabled them to "target small, local communities" and "invite to a workshop called 'Is your community ready?"” (P2; Appendix 5:6). The Resilience Assessment's analytical framework was open enough to host both global and local issues: Strengths and weaknesses of rural communities were also addressed, e.g., services disappearing (Appendix 5:7-8). Then, as one of the partners expressed it, "I can easier tie it (the global perspective) to the point where people already are" (P1). Compared with sustainability, resilience was a new concept that people had fewer preconceptions about (Appendix 5:9). One of the partners described it "as a possibility to use other arguments to advance the sustainability perspective," by appealing to long-term "security for people, or the rural community with surroundings" (P2; Appendix 5:6).

\section{Learning and participation in practice}

The Transition Movement approach complemented the Resilience Assessment with practical tools and exercises to strengthen learning and participation. Both partners stressed the importance of participation, e.g., by letting participants decide "resilience of what, to what," and emphasized the need for practical, pedagogical exercises in the workshop. Six exercises were used in the workshop (Appendix 2), three of which originated from the Transition Movement approach. For example, we adapted the Web of Resilience exercise from Hopkins (2008) and used it to illustrate diversity as an aspect of community resilience. Another exercise, developed by one of the partners, visualized thresholds and resilience, and was successful in starting a discussion among the participants about, e.g., what the system is and if resilience is always desirable (Appendix 5:11).

\section{Clarified transition focus}

The Transition Movement approach directed the Resilience Assessment workshop in a way that opened up for transition to sustainability. The partners actively promoted transition to sustainability (Appendix 5:13), exemplified by our project being a part of the broader "LEADER learns for transition to sustainability" project. Two examples of how this affected the workshop design were (1) that human needs were used as a starting point for resilience of what (Appendix 5:14), which opened up discussion about changing how needs are met, instead of limiting participants to current structures for meeting those needs; and (2) that we introduced climate change, peak oil, economics, global inequality, and the state of ecosystems in an exercise in the beginning of the workshop (context cards, Appendix 2), before 
the participants defined resilience to what. This exercise presented a negative picture of the current situation, and thereby promoted a need to change.

\section{Challenges}

The three main challenges we encountered in the case study related both to cross-fertilizing the approaches, as well as applying resilience thinking in participatory processes in general.

\section{Pedagogical challenge}

The partners recognized the pedagogical challenge of communicating new theoretical concepts, new ways of thinking, and global sustainability issues in a local context (Appendix 5:15-16). They realized that understanding resilience and complex systems is a learning process. Time is required to get familiar with new concepts, both for pedagogical exercises and individual reflection. Even though some participants demonstrated this understanding in the workshops, it became clear that expecting a deeper understanding of resilience from only one workshop was unrealistic.

\section{Expectations on quantitative outputs}

In the beginning, the partners had an ambition to substitute the traditional statistics in their organization's upcoming strategy document with statistics describing the resilience of their geographical area (Appendix 5:3). They wanted to do this in a participatory manner, by inviting local people to define resilience of what and to what, and then collect quantitative data related to the workshop output, which were categorized according to resilience characteristics (Appendix 3). However, many characteristics they were interested in assessing, e.g., economic modularity, were absent in existing statistics. Instead of spending time on a separate analysis, they decided that it was most important to generate an understanding of resilience thinking and focus on the learning process. In hindsight, one of the partners reflected on whether a factual report might have made a bigger impact on the upcoming strategy.

\section{Balancing openness and values}

Another challenge in the case study was how to balance the more open Resilience Assessment with the Transition Movement's values and assumptions about the future. The Transition Movement proposes specific things that need to be resilient, as well as what futures are seen as both likely and desirable (Hopkins 2008). The Resilience Assessment leaves the definition of what should be resilient and what futures are possible or desirable open, even though the process is framed by values of sustainable socialecological systems. One of the partners pointed out this difference by stating that "you cannot build a movement only on resilience...; we need to complement it with saying what it is that we value," whereas "this problem does not exist in the Transition Movement, because there it [resilience] is an integrated part, and not the only perspective", and there is also a strong justice perspective, for example (P1; Appendix 5:2). Our strategy to balance the approaches was to first introduce participants to global sustainability challenges, and then leave it open for them to identify their own potential future threats. However, this was a delicate balance. For example, one participant expressed feeling steered toward certain solutions by the global issues (Appendix $5: 17)$, at the same time as threats were identified during the more open session that did not directly align with the partners' intention to promote transition to sustainability, such as the risk of war.

\section{DISCUSSION}

Our results demonstrate that the Resilience Assessment and Transition Movement approaches have complementary strengths that could be integrated to improve the application of resilience thinking in participatory processes. Below we discuss how an integrated approach (1) strengthens the participatory learning process and fosters complex systems understanding, (2) generates context-specific understanding of resilience, and (3) better addresses transformations to global sustainability (Fig. 4). We also discuss additional challenges in applying resilience thinking highlighted by this study and suggest how they could be addressed.

Fig. 4. Integrating approaches to improve participatory resilience assessment. Illustrating how complementary strengths from the Transition Movement approach and the Resilience Assessment approach could be integrated to improve the application of resilience thinking, e.g., for communities, cities, and local governments.

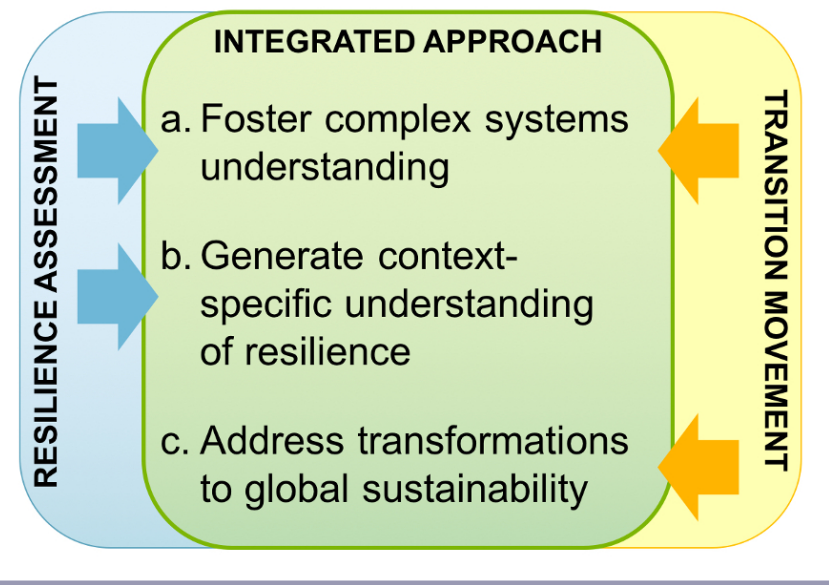

Synergies in fostering complex systems understanding

Both in comparing the written guidelines and in the case study, we found that the Transition Movement approach contributed practical knowledge on learning and participation to the Resilience Assessment. Although the Transition Movement aims to be inclusive, it has been criticized for lacking diversity (Smith 2011, Feola and Nunes 2014) and for focusing more on raising awareness than experiential learning (Seyfang and Haxeltine 2012). Nevertheless, in our study we found that the Transition Movement approach complemented the Resilience Assessment's lack of guidance on process design (Sellberg et al. 2015).

Combining the Transition Movement and Resilience Assessment approaches also created synergies in fostering complex systems understanding. The written guidelines of both approaches share a complex adaptive systems perspective (Fig. 3). However, our case study indicated that this understanding is not widely spread within the Transition Movement (Appendix 5:1). At the same time, complexity thinking has been identified as a key aspect of enhancing resilience thinking in the governance of socialecological systems (Biggs et al. 2015), and systems thinking as one of the teaching practices that can increase resilience (Spellman 2015). An integrated approach to applying resilience thinking could foster this understanding by combining the Resilience 
Assessment's complexity theory, e.g., the adaptive cycle and panarchy (Gunderson and Holling 2002), with the Transition Movement's pedagogical exercises on resilience and systems thinking. We started exploring this synergy at the workshops by combining a short presentation of complex systems with practical exercises to visualize thresholds and resilience. These exercises helped address the pedagogical challenges of communicating a new way of thinking to a diverse audience (Appendix 5:11) and could be further elaborated by using existing methods for teaching systems thinking, such as The Systems Thinking Playbook of Booth Sweeney and Meadows (2010).

\section{Generating context-specific understanding of resilience}

The Resilience Assessment approach provided a "conceptual and operational framework" that generated context-specific understanding of resilience, which Haxeltine and Seyfang (2009:20) argue the Transition Movement is lacking. In the workshops the Resilience Assessment did this in two main ways. First, it contributed a conceptual framework, including complex systems and resilience characteristics (Appendix 3), which was used to facilitate and clarify the meaning of resilience in practice. Second, it provided our partners with a stepwise process to explore the application of resilience for a particular context and location. The framework was open enough to host both local and global concerns, which helped them to address both local-regional rural development issues and global sustainability. Generating an understanding of resilience that is both locally embedded and linked to global sustainability issues is also interesting for the broader audience of communities, cities, and local governments who are working to apply resilience (e.g., UNISDR 2012, Rockefeller Foundation 2013).

Although we generated context-relevant understanding of resilience, we also learned that there is a need to manage expectations of quantitative outputs when applying resilience. There is a lot of interest in measuring resilience indicators (Quinlan et al. 2015), also from the Transition Movement (Hopkins 2008). Although a focus on measurable goals can be useful in well-understood situations when it is clear what to measure and how, it is less useful in situations with unclear goals and system definitions. Approaches to assess resilience can help clarify goals and useful system definitions, because they "focus on understanding the dynamics of social-ecological systems" (Quinlan et al. 2015:2). Quinlan et al. (2015) review approaches to assessing and measuring resilience. We agree with their conclusion that these approaches can be complementary, if the assessment is used to guide the construction of useful indicators. This corresponds to the focus of a recent framework building on the Resilience Assessment approach, which guides users in identifying the most relevant indicators for their context (O'Connell et al. 2015), in line with, e.g., the systems theory-based process for producing sustainability indicators of Meadows (1998) and the structured learning process of Strategic Adaptive Management (Biggs and Rogers 2003). Indicators can be linked to general concepts to enable cross-case comparisons (Quinlan et al. 2015). The disadvantage of such processes is that they require more time and resources, and therefore a careful process design.

\section{Addressing transformations to global sustainability}

Our comparison highlighted that the Resilience Assessment approach does not sufficiently address systemic transformations, nor how local places affect global sustainability (Fig. 3). This finding matches previous research stating that Resilience Assessment "has not adequately addressed the need for the deeper, more profound transformational change" in social-ecological systems (Walkerden et al. 2013:169). Despite resilience research emphasizing the need for deliberate transformations toward global sustainability (e.g., Gunderson and Holling 2002, Folke et al. 2010, Moore et al. 2014, Olsson et al. 2014), these ideas are not incorporated into the Resilience Assessment.

One possible explanation for this gap is that the Resilience Assessment has been primarily developed for regional natural resource management, where there is a strong emphasis on maintaining regional ecosystem services rather than on transformation (Appendix 1:1C). Current efforts to integrate transformational change in the Resilience Assessment focus on transformations of local-regional social-ecological systems, in order for the same systems to become sustainable over the long term (Walkerden et al. 2013, O'Connell et al. 2015). However, they do not explicitly address the local-regional transformations that need to happen to enhance planetary resilience (e.g., transforming to a low-carbon economy) and to avoid unwanted erosion of the resilience of other places (e.g., halting illegal ivory imports). On the contrary, the Transition Movement has adopted an interpretation of resilience that focuses on the root causes of environmental problems (Brown 2014, Cretney 2014, Cretney and Bond 2014). For example, it calls for a transformation away from societies' heavy dependence on cheap fossil fuels to avoid dangerous climate change globally (Appendix 1:1C). Addressing these issues is critical for assessing resilience in the Anthropocene, in which socially mediated interactions across scales and among distant places have increased in strength and variety (Steffen et al. 2011).

Incorporating transformation into resilience assessment Based on this study, we suggest that existing resilience research on transformation processes (e.g., Walkerden et al. 2013, Westley et al. 2013, Moore et al. 2014) should be better integrated into the Resilience Assessment approach. We also have three suggestions for addressing transformations to global sustainability in particular:

1. Resilience for what purpose? Define a purpose for assessing resilience that is guided by the need for transformations to global sustainability. Instead of leaving the purpose completely open for participants to define (Fig. 2, element A.1 in O'Connell et al. 2015), we believe that global sustainability should at least be considered. Otherwise, there is a risk of coming to conclusions that enhance resilience of the focal system, at least in the short term, but counteract sustainability globally, e.g., by increasing carbon emissions. In this study, we used the Transition Movement's narrative to communicate the need to assess resilience, which previously has been recognized to play a role in the success of transition initiatives (Feola and Nunes 2014). Placing resilience in a broader narrative is a way to give it meaning (Allen et al. 2005), but there needs to be an awareness of the fact that different actors have different narratives of pathways to sustainability (Leach et al. 2010).

2. Resilience of what and to what? Define resilience of what on a basic level, and include global sustainability and longer- 
term challenges in the discussion of resilience to what. The Resilience Assessment includes defining resilience of what and to what (sections 1.2 and 1.3 in Resilience Alliance 2010), corresponding to other assessment frameworks, e.g., of climate adaptation (Smit et al. 1999). In our case study, we framed what should be resilient as basic human needs, which opened up the possibility of changing current structures for providing for those needs. Guided by the Transition Movement's narrative, we introduced global sustainability challenges before defining resilience to what, although we also included local citizens' concerns about the future. Addressing resilience in a longer time perspective highlights the importance and potential of more transformative change (Meadows 1998). To balance values and openness, we suggest being guided by an overarching purpose of sustainable development, but discussing a variety of alternative future scenarios (Peterson et al. 2003, Enfors et al. 2008). This counteracts the risk that the Transition Movement approach runs of being unprepared for unexpected futures that do not correspond to their vision (Haxeltine and Seyfang 2009): a world with radically less energy and where the local level is much more important (Bailey et al. 2010).

3. Resilience where and on what scale? Assess how actions to build resilience at the focal scale affect resilience and sustainability in other places and on other scales, including the global scale. This could, for example, be included in the cross-scale analysis of the Resilience Assessment (Resilience Alliance 2010:30). A combination of a number of recent integrated frameworks and notions, such as multiscale resilience (Folke et al. 2010), cross-boundary interactions between systems (Fig. 4 in Rist et al. 2014), telecoupling (Liu et al. 2013), and a safe and just operating space for humanity (Raworth 2012, Steffen et al. 2015), provide a useful platform for doing this, because they capture different and complementary aspects.

Policy makers and practitioners in diverse fields are increasingly adopting the term "resilience" (e.g., Davoudi et al. 2012, Baggio et al. 2015), but interpretations range from preserving the status quo to being open for transformative change (Cretney 2014, Davidson et al. 2016). Our suggestions provide a starting point for further transdisciplinary research (Lang et al. 2012, Seidl et al. 2013) to cocreate transformational ways of applying resilience thinking. These types of applications are necessary, both in highly vulnerable and dynamic contexts (Davidson et al. 2016), and in response to the call of sustainability science for sustainability transitions (e.g., Kates et al. 2001).

We believe that further comparisons and cross-fertilizations of different approaches to applying resilience thinking and sustainability that bridge the science-practice divide are likely to yield additional insights that will advance sustainability science and practice. The relative and context-specific nature of such comparisons will reveal different strengths and weaknesses of the approaches (e.g., Feola 2014).

\section{CONCLUSION}

In this study, we have presented a novel cross-fertilization between two major approaches for applying resilience thinking: the Transition Movement (Hopkins 2008, 2011) and the Resilience
Alliance's Resilience Assessment (2010). Our findings highlight the possibility of improving the application of resilience thinking in participatory processes by integrating their complementary strengths: the Transition Movement's narrative of the need to transform in response to global sustainability challenges, as well as practical tools for learning and participation, with the Resilience Assessment's scientifically based framework and process for how to generate context-specific understanding of resilience. Combining the approaches also created synergies in fostering complex systems understanding. Our results show that the application of resilience thinking could be further improved by developing useful ways for how relevant indicators can be constructed through participatory learning processes.

Improving and adapting the application of resilience thinking are required in response to the growing demand from policy makers and practitioners for practical approaches to resilience across a variety of problem domains. This study demonstrates how a mutual learning process between two communities of practice created insights useful to the wider community working on applying resilience thinking for sustainable development. Therefore, we urge resilience practitioners and scientists to collaborate with one another to improve the theory and practice of resilience assessment and management for sustainability.

Responses to this article can be read online at: http://www.ecologyandsociety.org/issues/responses. $\mathrm{php} / 9051$

\section{Acknowledgments:}

We would like to thank all the participants at the workshops in the LEADER region for their openness and engagement. We are grateful for having had the opportunity to collaborate with our partner organization, Astrid Lindgrens Hembygd, and especially Hillevi Helmfrid and Daniel Hägerby who were the main organizers of this collaboration project and contributed much time, engagement and creativity. We thank Anna Helgeson, Megan Meacham, Lisen Schultz, Stephan Barthel, and Rebecka Milestad for useful comments, and Louise Hård af Segerstad for workshop assistance. This research was conducted under the SEEN (Social-Ecological dynamics of Ecosystem services in the Norrström basin) project, financed by the Swedish Research Council Formas (project no 2012-1058). This research contributes to the Program on Ecosystem Change and Society (www.pecs-science.org). Borgström was also supported by the COMPLEX project, funded by the EU FP7 (no 308601), and the ARTS project, funded by the EU FP7 (no 603654). The Stockholm Resilience Centre is funded by the Foundation for Strategic Environmental Research, Mistra.

\section{LITERATURE CITED}

Allen, T. F. H., A. J. Zellmer, and C. J. Wuennenberg. 2005. The loss of narrative. Pages 333-370 in K. Cuddington and B. E. Beisner, editors. Ecological paradigms lost: routes of theory change. Elsevier Academic Press, San Diego, California, USA. http://dx.doi.org/10.1016/b978-012088459-9/50017-0

Baggio, J. A., K. Brown, and D. Hellebrandt. 2015. Boundary object or bridging concept? A citation network analysis of 
resilience. Ecology and Society 20(2):2. http://dx.doi.org/10.5751/ ES-07484-200202

Bailey, I., R. Hopkins, and G. Wilson. 2010. Some things old, some things new: the spatial representations and politics of change of the peak oil relocalisation movement. Geoforum 41:595-605. http://dx.doi.org/10.1016/j.geoforum.2009.08.007

Biggs, H. C., and K. H. Rogers. 2003. An adaptive system to link science, monitoring, and management in practice. Pages 59-80 in J. T. Du Toit, K. H. Rogers, and H. C. Biggs, editors. The Kruger experience: ecology and management of savanna heterogeneity. Island Press, Washington, D.C., USA.

Biggs, R., M. Schlüter, and M. L. Schoon. 2015. Principles for building resilience-sustaining ecosystem services in socialecological systems. Cambridge University Press, Cambridge, UK. http://dx.doi.org/10.1017/CBO9781316014240

Booth Sweeney, L., and D. Meadows. 2010. The systems thinking playbook. Chelsea Green, White River Junction, Vermont, USA.

Brown, K. 2014. Global environmental change I: a social turn for resilience? Progress in Human Geography 38(1):107-117. http://dx. doi.org/10.1177/0309132513498837

Brunetta, G., and V. Baglione. 2013. Resilience in the Transition Towns movement. Towards a new urban governance. TeMA Journal of Land Use, Mobility and Environment 6(2):251-263. http://dx.doi.org/10.6092/1970-9870/1524

Charmaz, K. 2006. Constructing grounded theory: a practical guide through qualitative analysis. Sage, Thousand Oaks, California, USA.

Connors, P., and P. McDonald. 2011. Transitioning communities: community, participation and the Transition Town movement. Community Development Journal 46(4):558-572. http://dx.doi. org $/ 10.1093 / \mathrm{cdj} / \mathrm{bsq} 014$

Cretney, R. 2014. Resilience for whom? Emerging critical geographies of socio-ecological resilience. Geography Compass 8 (9):627-640. http://dx.doi.org/10.1111/gec3.12154

Cretney, R., and S. Bond. 2014. 'Bouncing back' to capitalism? Grass-roots autonomous activism in shaping discourses of resilience and transformation following disaster. Resilience 2 (1):18-31. http://dx.doi.org/10.1080/21693293.2013.872449

Davidson, J. L., C. Jacobson, A. Lyth, A. Dedekorkut-Howes, C. L. Baldwin, J. C. Ellison, N. J. Holbrook, M. J. Howes, S. SerraoNeumann, L. Singh-Peterson, and T. F. Smith. 2016. Interrogating resilience: toward a typology to improve its operationalization. Ecology and Society 21(2):27. http://dx.doi. org/10.5751/ES-08450-210227

Davoudi, S., K. Shaw, L. J. Haider, A. E. Quinlan, G. D. Peterson, C. Wilkinson, H. Fünfgeld, D. McEvoy, L. Porter, and S. Davoudi. 2012. Resilience: a bridging concept or a dead end? Planning Theory \& Practice 13(2):299-307. http://dx.doi.org/10.1080/146$\underline{49357.2012 .677124}$

Enfors, E. I., L. J. Gordon, G. D. Peterson, and D. Bossio. 2008. Making investments in dryland development work: participatory scenario planning in the Makanya catchment, Tanzania. Ecology and Society 13(2):42. [online] URL: http://www.ecologyandsociety. org/voll3/iss2/art42/
Esaiasson, P., M. Gilljam, H. Oscarsson, and L. Wängnerud. 2007. Kvalitativ textanalys. Pages 237-256 in P. Esaiasson, M. Gilljam, H. Oscarsson, and L. Wängnerud, editors. Metodpraktikan: konsten att studera samhälle, individ och marknad. Third edition. Norstedts Juridik, Stockholm, Sweden.

European Commission. 2016. LEADER/CLLD. European Network for Rural Development, Brussels, Belgium. Available at: http://enrd.ec.europa.eu/leader-clld en

Feola, G. 2014. Narratives of grassroots innovations: a comparison of Voluntary Simplicity and the Transition Movement in Italy. International Journal of Innovation and Sustainable Development 8(3):250-269. http://dx.doi.org/10.1504/ ijisd.2014.066612

Feola, G., and R. Nunes. 2014. Success and failure of grassroots innovations for addressing climate change: the case of the Transition Movement. Global Environmental Change 24:232-250. http://dx.doi.org/10.1016/j.gloenvcha.2013.11.011

Folke, C. 2006. Resilience: the emergence of a perspective for social-ecological systems analyses. Global Environmental Change 16:253-267. http://dx.doi.org/10.1016/j.gloenvcha.2006.04.002

Folke, C., S. R. Carpenter, B. Walker, M. Scheffer, T. Chapin, and J. Rockström. 2010. Resilience thinking: integrating resilience, adaptability and transformability. Ecology and Society 15(4):20. [online] URL: http://www.ecologyandsociety.org/vol15/iss4/ $\underline{\operatorname{art} 20 /}$

Friese, S. 2012. Qualitative data analysis with Atlas.ti. Sage, Los Angeles, California, USA.

Glaser, B. G. 1998. Doing grounded theory: issues and discussions. Sociology Press, Mill Valley, California, USA.

Gunderson, L., and C. S. Holling, editors. 2002. Panarchy: understanding transformations in human and natural systems. Island Press, Washington, D.C., USA.

Haider, L. J., A. E. Quinlan, and G. D. Peterson. 2012. Interacting traps: resilience assessment of a pasture management system in northern Afghanistan. Planning Theory \& Practice 13(2):312-319. http://dx.doi.org/10.1080/14649357.2012.677124

Haxeltine, A., and G. Seyfang. 2009. Transitions for the people: theory and practice of 'transition' and 'resilience' in the UK's Transition Movement. Working Paper 134. Tyndall Centre for Climate Change Research, Norwich, UK.

Hopkins, R. 2008. The transition handbook: from oil dependency to local resilience. Green Books, Totnes, UK.

Hopkins, R. 2009. Resilience thinking: why 'resilience thinking' is a crucial missing piece of the climate-change jigsaw and why resilience is a more useful concept than sustainability. Resurgence 257:12-15.

Hopkins, R. 2011. The transition companion: making your community more resilient in uncertain times. Chelsea Green, White River Junction, Vermont, USA.

Jorgensen, D. L., editor. 1989. Participant observation. Sage, Thousand Oaks, California, USA. http://dx.doi. org/10.4135/9781412985376 
Kates, R. W., W. C. Clark, R. Corell, J. M. Hall, C. C. Jaeger, I. Lowe, J. J. McCarthy, H. J. Schellnhuber, B. Bolin, N. M. Dickson, S. Faucheux, G. C. Gallopin, A. Grübler, B. Huntley, J. Jäger, N. S. Jodha, R. E. Kasperson, A. Mabogunje, P. Matson, H. Mooney, B. Moore III, T. O'Riordan, and U. Svedin. 2001. Sustainability science. Science 292(5517):641-642. http://dx.doi.org/10.1126/ $\underline{\text { science. } 1059386}$

Kvale, S., and S. Brinkmann. 2009. Interviews: learning the craft of qualitative research interviewing. Second edition. Sage, Thousand Oaks, California, USA.

Lang, D. J., A. Wiek, M. Bergmann, M. Stauffacher, P. Martens, P. Moll, M. Swilling, and C. J. Thomas. 2012. Transdisciplinary research in sustainability science: practice, principles, and challenges. Sustainability Science 7(1):25-43. http://dx.doi. org/10.1007/s11625-011-0149-X

Leach, M., I. Scoones, and A. Stirling. 2010. Dynamic sustainabilities: technology, environment, social justice. Earthscan, Abingdon, UK.

Liu, J., V. Hull, M. Batistella, R. DeFries, T. Dietz, F. Fu, T. W. Hertel, R. C. Izaurralde, E. F. Lambin, S. Li, L. A. Martinelli, W. J. McConnell, E. F. Moran, R. Naylor, Z. Ouyang, K. R. Polenske, A. Reenberg, G. de Miranda Rocha, C. S. Simmons, P. H. Verburg, P. M. Vitousek, F. Zhang, and C. Zhu. 2013. Framing sustainability in a telecoupled world. Ecology and Society 18 (2):26. http://dx.doi.org/10.5751/ES-05873-180226

Liu, W. 2014. The application of resilience assessment-resilience of what, to what, with what? A case study based on Caledon, Ontario, Canada. Ecology and Society 19(4):21. http://dx.doi. org/10.5751/ES-06843-190421

Max-Neef, M. A., with contributions from A. Elizalde and M. Hopenhayn. 1991. Human scale development: conception, application and further reflections. Apex, New York, New York, USA.

Meadows, D. 1998. Indicators and information systems for sustainable development. The Sustainability Institute, Hartland Four Corners, Vermont, USA. [online] URL: http:// donellameadows.org/wp-content/userfiles/IndicatorsInformation. pdf

Mitchell, M., R. Griffith, P. Ryan, G. Walkerden, B. Walker, V. A. Brown, and S. Robinson. 2014. Applying resilience thinking to natural resource management through a "planning-by-doing" framework. Society \& Natural Resources: An International Journal 27(3):299-314. http://dx.doi.org/10.1080/08941920.2013.861556

Moore, M.-L., O. Tjornbo, E. Enfors, C. Knapp, J. Hodbod, J. A. Baggio, A. Norström, P. Olsson, and D. Biggs. 2014. Studying the complexity of change: toward an analytical framework for understanding deliberate social-ecological transformations. Ecology and Society 19(4):54. http://dx.doi.org/10.5751/ ES-06966-190454

O'Connell, D., B. Walker, N. Abel, and N. Grigg. 2015. Planning for resilience in a rapidly changing world-The Resilience Adaptation and Transformation Assessment Framework (RAPTA). CSIRO, Australia. [online] URL: http://www.stapgef. org/the-resilience-adaptation-and-transformation-assessment-framework
Olsson, P., V. Galaz, and W. J. Boonstra. 2014. Sustainability transformations: a resilience perspective. Ecology and Society 19 (4):1. http://dx.doi.org/10.5751/ES-06799-190401

Peterson, G. D., G. S. Cumming, and S. R. Carpenter. 2003. Scenario planning: a tool for conservation in an uncertain world. Journal of the Society for Conservation Biology 17:358-366. http:// dx.doi.org/10.1046/j.1523-1739.2003.01491.x

Quinlan, A. E., M. Berbés-Blázquez, L. J. Haider, and G. D. Peterson. 2015. Measuring and assessing resilience in practice: broadening understanding through multiple disciplinary perspectives. Journal of Applied Ecology. 53:677-687. http://dx. doi.org/10.1111/1365-2664.12550

Raworth, K. 2012. A safe and just space for humanity: can we live within the doughnut? Oxfam discussion paper. Oxfam Policy and Practice: Climate Change and Resilience 8(1):1-26. [online] URL: http://www.ingentaconnect.com/content/oxpp/ oppccr/2012/00000008/00000001/art00001

Resilience Alliance. 2010. Assessing resilience in social-ecological systems: workbook for practitioners. Version 2.0. [online] URL: http://www.resalliance.org/resilience-assessment

Resilience Alliance. 2016. Resilience assessment projects. [online] URL: http://www.resalliance.org/apps/raprojects/pr-map.php

Rist, L., A. Felton, M. Nyström, M. Troell, R. A. Sponseller, J. Bengtsson, H. Österblom, R. Lindborg, P. Tidåker, D. G. Angeler, R. Milestad, and J. Moen. 2014. Applying resilience thinking to production ecosystems. Ecosphere 5:1-11. http://dx.doi. org/10.1890/ES13-00330.1

Rockefeller Foundation. 2013. Rebound: building a more resilient world. Rockefeller Foundation, New York, New York, USA. [online] URL: https://assets.rockefellerfoundation.org/app/ uploads/20130124192107/Rebound-Building-a-More-Resilient-World-. pdf

Seidl, R., F. S. Brand, M. Stauffacher, P. Krütli, Q. B. Le, A. Spörri, G. Meylan, C. Moser, M. Berger González, and R. Werner Scholz. 2013. Science with society in the Anthropocene. Ambio 42:5-12. http://dx.doi.org/10.1007/s13280-012-0363-5

Sellberg, M. 2013. Resilience in practice for strategic planning at a local government. Thesis. Stockholm University, Stockholm, Sweden.

Sellberg, M. M., C. Wilkinson, and G. Peterson. 2015. Resilience assessment: a useful approach for navigating urban sustainability challenges. Ecology and Society 20(1):43. http://dx.doi. org/10.5751/ES-07258-200143

Seyfang, G., and A. Haxeltine. 2012. Growing grassroots innovations: exploring the role of community-based initiatives in governing sustainable energy transitions. Environment and Planning C: Government and Policy 30:381-400. http://dx.doi. org/10.1068/c10222

Smit, B., I. Burton, R. Klein, and R. Street. 1999. The science of adaptation: a framework for assessment. Mitigation and Adaptation Strategies for Global Change 4:199-213. http://dx.doi. org/10.1023/A:1009652531101 
Smith, A. 2011. The Transition Town network: a review of current evolutions and renaissance. Social Movement Studies: Journal of Social, Cultural and Political Protest 10(1):99-105. http://dx.doi. org/10.1080/14742837.2011.545229

Spellman, K. V. 2015. Educating for resilience in the North: building a toolbox for teachers. Ecology and Society 20(1):46. http://dx.doi.org/10.5751/ES-07243-200146

Statistics Sweden (SCB). 2010. Folkmängden per tätort. Vart femte år 1990-2010. [online] URL: http://www.statistikdatabasen.scb. se/pxweb/sv/ssd/START_BE BE0101 BE0101A/FolkmangdTatort/ table/tableViewLayout1/?rxid=4538b8c3-0aa9-480c-9a0e-02e3d4a9ad00

Steffen, W., Å. Persson, L. Deutsch, J. Zalasiewicz, M. Williams, K. Richardson, C. Crumley, P. Crutzen, C. Folke, L. Gordon, M. Molina, V. Ramanathan, J. Rockström, M. Scheffer, H. J. Schellnhuber, and U. Svedin. 2011. The Anthropocene: from global change to planetary stewardship. Ambio 40(7):739-761. http://dx.doi.org/10.1007/s13280-011-0185-x

Steffen, W., K. Richardson, J. Rockström, S. E. Cornell, I. Fetzer, E. M. Bennett, R. Biggs, S. R. Carpenter, W. de Vries, C. A. de Wit, C. Folke, D. Gerten, J. Heinke, G. M. Mace, L. M. Persson, V. Ramanathan, B. Reyers, and S. Sörlin. 2015. Planetary boundaries: guiding human development on a changing planet. Science 347(6223):1259855. http://dx.doi.org/10.1126/science.1259855

Transition Culture. 2017. The transition companion. [online] URL: https://www.transitionculture.org/shop/the-transition-companion

Transition Network. 2016. . Transition near me. [online] URL: https://transitionnetwork.org/transition-near-me/

United Nations Office for Disaster Risk Reduction (UNISDR). 2015. Making cities resilient: my city is getting ready. UNISDR, Geneva, Switzerland. [online] URL: https://www.unisdr.org/ campaign/resilientcities/

UNU-IAS, Bioversity International, IGES, and UNDP. 2014. Toolkit for the indicators of resilience in socio-ecological production landscapes and seascapes (SEPLS).. [online] URL: http://bit. ly/1wskSgu

Wagenaar, H. 2011. Strategies of interpretive policy research. Pages 241-274 in H. Wagenaar, editor. Meaning in action: interpretation and dialogue in policy analysis. M.E. Sharpe, Armonk, New York, USA.

Walker, B., S. Carpenter, J. Anderies, N. Abel, G. S. Cumming, M. Janssen, L. Lebel, J. Norberg, G. D. Peterson, and R. Pritchard. 2002. Resilience management in social-ecological systems: a working hypothesis for a participatory approach. Conservation Ecology 6(1):14. [online] URL: http://www. consecol.org/vol6/iss1/art14/

Walker, B., and D. Salt. 2006. Resilience thinking: sustaining ecosystems and people in a changing world. Island Press, Washington, D.C., USA.

Walker, B. H., N. Abel, J. M. Anderies, and P. Ryan. 2009. Resilience, adaptability, and transformability in the GoulburnBroken Catchment, Australia. Ecology and Society 14(1):12. [online] URL: http://www.ecologyandsociety.org/vol14/iss1/ $\underline{\operatorname{art12l}}$
Walker, B., and D. Salt. 2012. Resilience practice: building capacity to absorb disturbance and maintain function. Island Press, Washington, D.C., USA. http://dx.doi.org/10.5822/978-1-61091-231-0

Walkerden, G., P. Ryan, R. Griffith, and S. Robinson. 2013. Exploring transformation for resilient Australian landscapes and communities. Pages 169-177 in Proceedings of Transformation in a Changing Climate. 19-21 June 2013, University of Oslo, Oslo, Norway.

Westley, F. R., O. Tjornbo, L. Schultz, P. Olsson, C. Folke, B. Crona, and Ö. Bodin. 2013. A theory of transformative agency in linked social-ecological systems. Ecology and Society 18(3):27. http://dx.doi.org/10.5751/ES-05072-180327

Xu, L., and D. Marinova. 2013. Resilience thinking: a bibliometric analysis of socio-ecological research. Scientometrics 96(3):911-927. http://dx.doi.org/10.1007/s11192-013-0957-0 


\section{Appendix 1. Qualitative text analysis}

Description and results (Table A1.1) from the qualitative text analysis, which allowed us to identify distinctions and commonalities between the Transition Movement approach and the Resilience Assessment approach, through comparing their respective written guidelines (i.e. Resilience Alliance 2010, and Hopkins 2008, 2011).

\section{Process and framework}

In line with Esaiasson et al. (2007), the qualitative text analysis consisted of a careful reading of the text, with respect to its parts, the whole and its context, in order to highlight and make sense of the content that was relevant to our research question. It was an iterative process of reading through the material thoroughly while taking notes, and then returning to different parts of it over and over. To ensure the validity of our results, we focused on findings that were repeated throughout the material and that were clearly expressed in the texts.

We developed a framework to structure the comparison (Esaiasson et al. 2007), based on existing frameworks and principles (e.g., Leach et al. 2010, Biggs et al. 2015), a recent study of a resilience assessment process (Sellberg et al. 2015), and the preliminary case study findings (Table 1). In order to not miss interesting findings, we also included interpretations of resilience in practice that emerged from the text analysis.

The first category (1. Narrative) included a brief narrative analysis, which helped provide a context for the rest of the findings (Table 1). This approach builds on Leach et al. (2010)'s framework, which focuses on alternative narratives of pathways to sustainability. Narratives both "define a problem, explain how it comes about and show what needs to be done to avert disaster or bring about a happy ending: in other words, what is wrong and how it must be put right" (Leach et al. 2010:130). Based on this definition, we used "what is the problem and what should be done about it?" as a guiding question to distill narratives from the texts.

The second category (2. Definition and use of resilience concept) clarified the different interpretations of resilience (Table 1). The sub-categories captured how resilience is defined, the scope of what it is that should be resilient, and to what (Resilience Alliance 2010), if persistence, adaptability, or transformability are emphasized as aspects of resilience (Folke et al. 2010), and how resilience is interpreted in practice, using the resilience principles in Biggs et al. (2015). Transformability is the ability "to create a fundamentally new system when ecological, economic, or social structures make the existing system untenable" (Folke et al. 2010).

Based on the case study, as well as a recent study of a resilience assessment process (Sellberg et al. 2015), we expected the Transition Movement approach to focus more on practical tools. We also expected the Resilience Assessment to have a stronger theoretical foundation, especially with 
respect to social-ecological interactions and cross-scale connections. Therefore, we also included this as a third category in the text analysis framework (3. Emphasis on theory vs. practical tools, Table 1).

\section{Table A1.1. Results from the qualitative text analysis}

\begin{tabular}{|c|c|c|}
\hline & $\begin{array}{c}\text { Transition Movement Approach } \\
\text { (Hopkins 2008, 2011) }\end{array}$ & $\begin{array}{c}\text { Resilience Assessment Approach } \\
\text { (Resilience Alliance 2010) }\end{array}$ \\
\hline \multicolumn{3}{|l|}{ 1. Narrative } \\
\hline A. Goal & $\begin{array}{l}\text { Make communities sustainable and achieve global } \\
\text { sustainability (incl. environmental, social justice, and human } \\
\text { well-being dimensions) (e.g., 2011:28 and 39). }\end{array}$ & $\begin{array}{l}\text { Sustain the long-term capacity of social-ecological systems } \\
\text { to deliver environmental benefits linked to human-wellbeing } \\
\text { (p. 4). }\end{array}$ \\
\hline $\begin{array}{l}\text { B. System } \\
\text { delimitation }\end{array}$ & $\begin{array}{l}\text { Local scale communities across the globe, but with focus on } \\
\text { Western World, and global scale changes, e.g. climate } \\
\text { change. }\end{array}$ & $\begin{array}{l}\text { Local and regional natural resource management across the } \\
\text { globe. }\end{array}$ \\
\hline $\begin{array}{l}\text { C. Narrative } \\
\text { summary }\end{array}$ & $\begin{array}{l}\text { Our societies dependence on heavy use of fossil fuels means } \\
\text { that "we're likely to run into /.../ dangerous climate change } \\
\text { and an energy famine when oil reserves run low" (2008:86). } \\
\text { Therefore, we need to "move rapidly to a zero carbon } \\
\text { society" (2008:142), and since there is no substitute for } \\
\text { cheap liquid fossil fuels on the scale we use them, we need } \\
\text { urgently to prepare for a future with less energy. Our } \\
\text { communities also have become dependent on the global } \\
\text { economy. We need to rebuild the resilience of our } \\
\text { communities, through the measures above, as well as through } \\
\text { e.g. strengthening the local economy, local production of } \\
\text { essentials, and social networks. These enormous changes } \\
\text { imply a major transition of our culture, economy and } \\
\text { infrastructure, but if we plan proactively and creatively, there }\end{array}$ & $\begin{array}{l}\text { The problem is increasing environmental change and loss of } \\
\text { resilience in social-ecological systems to that change, which } \\
\text { could lead to undesired shifts in social-ecological systems. } \\
\text { Loss of resilience threatens the long-term capacity of social- } \\
\text { ecological systems to deliver environmental benefits linked } \\
\text { to human-wellbeing, and this loss is often caused or } \\
\text { worsened by traditional management. Therefore, we need } \\
\text { another natural resource management that is based on a } \\
\text { social-ecological systems framework and an understanding } \\
\text { of how to cope with change and uncertainty. This type of } \\
\text { natural resource management can enhance/maintain } \\
\text { resilience of desired system states. Performing resilience } \\
\text { assessments of those systems will generate the type of } \\
\text { system understanding needed, which should be used as a }\end{array}$ \\
\hline
\end{tabular}


is a possibility for a more desirable future than the present. Communities need to take a leading role in this transition, since e.g. governments won't dare take the steps necessary if they don't have the public's support. So far, environmental campaigns have failed to engage enough people on the scale required and we need a new approach - the Transition approach, using e.g. positive visioning, insights from psychology, and inclusive processes, and build a global movement around it. decision basis for new management strategies that enhance/maintain resilience.

\section{Definition and use of resilience concept}

\section{A. Definition of \\ "...the capacity of an individual, community or system to} resilience adapt in order to sustain an acceptable level of function, structure and identity" (2011:45)

Community resilience is "the ability of a community to withstand external shocks and stresses without significant upheaval", and also adding that a resilient community would have "a resilient and accessible resource base and a dynamic range of viable livelihood and responsive institutions" (Adger 2002, cited in 2011:44).

B. Resilience of what, to what

C. Emphasis on persistence, adaptability, or transformability
Resilience of communities' abilities to "sustain life and thrive" (2011:13) in the face of peak oil, climate change and disruptions in the global economic system

- Persistence of communities (see 2B)

- Adaptability in the transition process and as key aspect of resilience

- Transformability is necessary for becoming resilient
"Resilience is fundamentally a system property. It refers to the magnitude of change or disturbance that a system can experience without shifting into an alternate state that has different structural and functional properties and supplies different bundles of the ecosystem services that benefit people." (p. 5)

Resilience of key components of SES, i.e. natural resources and ecosystem services that stakeholders rely on, to disturbances, disruptions and uncertainty (p. 15)

- Persistence of natural resources and ecosystem services (see 2B)

- Adaptability in the assessment process and in governance and as key aspect of resilience 
as aspects of

resilience

D. Interpretation

of resilience in

practice, based on

principles for

resilience
- Transformability needed if existing structures become untenable (p. 48)

\section{Maintain diversity and redundancy}

Diversity is part of the permaculture framework

underpinning the approach and increased diversity is

addressed as part of building resilience (see narrative, 1C).

The approach promotes e.g. diversification of local and rural

economies, food and energy sources, and a diversity of

solutions in different communities.

\section{Manage connectivity}

Increased modularity is addressed as part of building

Modularity is addressed as part of general resilience

resilience (see narrative, 1C), through decreasing functional

dependencies to the global systems, and rebuilding

connections and social networks within the community.

The movement itself also has a modular, network structure.

\section{Manage slow variables and feedbacks}

Not thoroughly theorized, but addresses e.g. reinforcing mechanisms of climate change and the current regime,

changes in slow variables, such as culture and values, and maintenance of regulating ecosystem services (one of the permaculture principles). Emphasis is on tightening

feedbacks, as part of building resilience, through

localization, which will make the "results of our actions /.../

Diversity is part of general resilience attributes and the stewardship strategies (table 4, p. 47).
Key part of Resilience Assessment framework, e.g. socialecological systems (figure 2), and process, e.g. key feedbacks and slow variables are supposed to end up in the conceptual model constructed through the Resilience Assessment process.

Tightness of feedbacks is a general resilience attribute.

more obvious" (2008:56).

The movement itself is providing a feedback through responding to slow environmental changes. 
4. Foster an understanding of social-ecological systems as complex adaptive systems

Part of the philosophical underpinnings (permaculture principles and idea of self-organizing systems), manifested through focus on e.g. resilience to changes, locally adapted and self-organizing responses, exploring scenarios of how peak oil and climate change will play out, and by visualizing tipping points in the pedagogical tool "the web of resilience exercise" (2008:60).

\section{Encourage learning and experimentation}

Key strategy of the approach: communities need to learn and adapt in order to be resilient, and collective learning (incl.

triple-loop) and innovation is also needed for an intentional transition. Hopkins (2011) provides a lot of tools and ingredients to encourage learning and self-reflection (individually and collectively) within the movement. Experimentation encouraged e.g. through the non-

hierarchical organization, seeing the whole movement as an experiment, emphasizing "learning by doing", and the opensource approach.

\section{Broaden participation}

Key strategy of the approach: "we need to be generating a response on a previously unseen scale" (2008:76) in order to meet the scale of the challenges and transition successfully. The potential of Transition initiatives is to "create a truly community-led process" (2008:144) and inclusion and diversity are essential for the success of an initiative.
Part of Resilience Assessment framework, (e.g., p. 7) and the assessment is about creating this type of understanding of the focal system.

Learning approach focuses on explaining theoretical concepts and giving examples of how they are applied to a case, lacking experience-based pedagogical tools.
Promoting adaptive governance and management, which are characterized by experimentation and learning.

Monitoring to increase understanding of the system.

The assessment process is intended to be reflexive and iterative (e.g. by encouraging to "reflect and connect" in the end of each section), and promote learning, from first to third loop.
Many of activities require a "diversity of perspectives" and insights from both scientific and local knowledge (e.g. identifying main issues and related values).

Exercises for mapping the key stakeholders and social networks.

Effective stakeholder participation and collaborative 
Provides multiple strategies and tools for how to engage people and make participation successful, e.g. strive for inclusivity (e.g. through open space processes), use psychological insights, and build social networks.

\section{Promote poly-centric governance}

Promoting poly-centricity through the network structure within the movement and the initiatives, e.g. the "Project Support Project concept" (2008:142), and by advocating local responses that act in parallel but in collaboration with government at different levels.

Addresses the scale-mismatch between global climate change and resource depletion, and local action, e.g. by promoting a global movement of local responses (2008: Ch. 13).

\section{E. Other} interpretations of resilience in practice, emerging from text analysis

\section{Power and influence}

Community-scale resilience involves that the community regains a certain degree of influence, by e.g. having locally owned businesses (2008:57), and the devolution of powers to local communities (2008:75). This is even more emphasized in Hopkins (2011), reflected e.g. in adding the subsidiarity principle to the principles of transition (p. 78). Resilience means independence, which implies ability to make decisions and shape your own responses.

\section{Capitals}

Different forms of capital as increasing resilience, e.g.

financial capital (2008:40), which also is a requirement for processes is required to manage for resilience and ecosystem-based stewardship.

Nothing about how (or if) to include participants in the process, who to invite, how to design the process.

Theory on governance systems is addressed, with emphasis on adaptive governance, institutions and social networks $(\mathrm{Ch}$. 4).

Promoting polycentric governance as a stewardship strategy (table 4, p. 47).

Addresses social-ecological-mismatches e.g. in Grand Canyon example (p. 10) and in the assessment exercise on $p$. 38.

Differences in power and influence over resource use are to be mapped and discussed in the assessment, as well as conflicts (p. 38-39), but not clear how that relates to the resilience of the system.
Various forms of capital, mainly social, addressed as part of transformability (p. 48-50). Social capital (e.g. trust, 
successful localization (2011:287), and social capital, reflected in e.g. re-building social networks in a community (e.g., 2008:60). leadership, social networks) also brought up as a stewardship strategy (table 4, p. 47).

\section{Emphasis on theory vs. practical tools}

A. Activities and Activities for the collective transition process, with Hopkins methods included (2011) expanding with activities further on in the transition in the different approaches

B.

Conceptualization of socialecological interactions process: not only preparing the system for change and raising awareness and building networks, but actually starting to e.g. build the alternative infrastructure, and to formalize and scale up initiatives.

In Hopkins (2008), transition is described through twelve steps, but in Hopkins (2011) this is developed into a cookbook of practical ingredients and tools divided into the sections: starting out, deepening, connecting, building, and daring to dream. The task is to navigate the local context using the tools and ingredients.

Human-nature interdependence recognized in the ideas that underpin the approach, e.g. the permaculture principles and tools. Focus on resilience of communities and not of socialecological systems, but Hopkins (2011) adds that a resilient community would have "a resilient and accessible resource base" (see 2A).

The practical manifestations has potential to strengthen peoples' relation to essential ecosystem services, mostly by involving more people in the generation of ecosystem
An assessment process, which includes describing the system, understanding the system and its dynamics (incl. e.g. cross-scale interactions and governance), and synthesizing and acting on the assessment (Figure 1, p. 5). The output from the first two steps is two diagrams: a conceptual model of the social-ecological system, and a diagram of the identified threshold effects (p. 43), which forms a basis for developing strategies for coping with change. The process goes through the key concepts of the framework and applies them to the focal system, in successively more theoretical depth.

Each section of the workbook goes through: theory, an example from another case, assessment questions, discussion, reflect and connect, and summarize.

At the core of the Resilience Assessment framework (figure 2, p. 6) and significant throughout the workbook in all of the assessment exercises.

Social-ecological interactions part of the focus on socialecological systems components (resilience of what) and the sustainability goal.

Adaptive management has potential to emphasize "the capacity to adapt to changing relationships between society and ecosystems in ways that sustain ecosystem services" (p. 
services, such as food, and by moving it closer to people.

C.

Conceptualization of cross-scale interactions
Promotes a community-led response within a

global/international perspective. Recognizes need for scaling up movement, but recommends to grow from the bottom up through creating networks across scales. Acknowledging both support and constraints from government at different scales, and that "any successful response needs to operate on a range of scales" (2011:53).
8).

At the core of the Resilience Assessment framework (Ch. 3), e.g. the panarchy concept, managing social-ecological systems requires understanding of cross-scale interactions, which is a mix of bottom-up and top-down processes. 


\section{Appendix 2. The workshop}

Description of the workshop developed and performed with the partner organization in Southern Sweden as a part of the case study, how it was conducted as well as the workshop agenda (Table A2.1).

The one-day workshop was developed together with the two collaborators from the partner organization and performed on three occasions, January-April 2014, at different locations within the region. 17-34 people participated at each workshop (72 participants in total). Our partners took the main responsibility for facilitating the workshops, whereas one of the coauthors contributed with a couple of short presentations and assisted at some of the exercises. In the end of each workshop, all participants took part in a reflection round that was recorded and transcribed.

The first workshop in January was a pilot, and for the next couple of workshops in April we refined some of the exercises and developed a folder on resilience (Appendix 3). Repeating the workshop with different participants allowed us to successively refine the workshop agenda, and generated more reliable results of benefits and challenges. For the partners, the workshops were part of their work in the project "LEADER learns for transition to sustainability".

It is important to note that this is not the only way to combine the two approaches, and that the specific contributions of the two approaches (see results on the benefits of crossfertilization) will depend on the specific case. They will also vary depending on which approach you compare it to, showed for example in the results of Feola (2014), comparing the Transition Movement in Italy to another grassroots initiative: the voluntary simplicity movement in Italy.

\section{Table A2.1. The workshop agenda}

\subsection{Introduction:}

Presentation round, aim of the workshop

\section{$9.40 \quad$ Intro Resilience I:}

"Web of resilience" exercise (adaptation from Hopkins 2008, p. 60), starting point: what is needed for a viable local community? Historical perspective: how has the web changed over time? (influenced by the historical timeline exercise in Resilience Alliance 2010, section 1.4)

Lessons for resilience: networks with a diversity of connections and relations, unpredictable when the network collapses

\subsection{Trends and threats:}

Exercise with "context cards", describing problems of climate change, peak oil, global economy, global inequality, and ecosystem deterioration (developed by one of the partners based on an idea from the UK Transition Movement). The workshop is about preparing for surprise, both slow and fast changes. The cards address some of them.

Lessons for resilience: Everything is connected, social-ecological systems, cannot solve one problem without affecting the others 


\subsection{Human needs:}

Exercise on human needs: What are our basic needs that we want to be able to meet also in the future?

Placing needs in the framework of Max-Neef (1991): needs are a few, finite and the same across cultures. Not hierarchical, but more like a system, or glasses on a tray that needs to be balanced.

Discussion of difference between needs and strategies to meet the needs.

\subsection{LUNCH}

\subsection{Intro resilience II:}

Definition of a resilient local community (translated from Swedish): "a resilient local community can thrive and meet people's needs, even with changing conditions in the world surrounding it, and regardless what the future will look like" Demonstration of threshold effects (Resilience Alliance 2010, section 2.3) by blowing up a balloon...

Presentation on seeing the world as complex systems and strategies for how to deal with complexity (drawing on the Resilience Assessment's underpinning idea of complex adaptive systems (Resilience Alliance, p. 4)).

Exercise on resilience: a group standing around a sheet, holding the edges, representing external changes, chairs beneath the sheet as thresholds, playing around with balls of different weights.

Lessons for resilience: complexity, fluctuations, disturbances and critical limits

\subsection{Resilience to what?}

Threats: Individual reflection, putting threats on the wall, discussion

\subsection{Resilience of what?}

What do we want to be resilient? Values.

What is it that we want to preserve in this local community? What are conditions for good life quality and a thriving local community?

Using the needs from before as a starting point, placing the prioritized ones in the middle, complementing.

\subsection{Intro resilience III:}

Presentation of cross-scale interactions, different scales are interconnected (Resilience Alliance 2010, section 3), modularity (example from Hopkins 2008, p. 59).

Lessons for resilience: enough self-sufficiency, not isolated, but not too dependent either, modularity and redundancy

\subsection{Strengths and weaknesses:}

Individual exercise: selecting important needs and the threats that threaten it. Connecting needs and threats in groups, identifying related strengths and weaknesses from a resilience perspective.

Summary and reflection of strengths and weaknesses, what perspectives are missing? 


\subsection{Strategies for resilience:}

Presentation of resilience folder and general characteristics for resilient systems (Appendix 3).

Going through the resilience characteristics in groups - relate to local community: what do we have already and what could we add? Is it relevant for us?

\subsection{Reflection round and evaluation}




\section{Appendix 3. Characteristics of a resilient system}

List of resilience characteristics developed with the partners and used in the workshops.

This list of "characteristics of a resilient system" was developed together with the partners in Swedish. The list was part of a folder that introduced resilience, and explained and exemplified each of the characteristics. We used the list in the workshops, where the participants filled in existing and suggested future actions related to each of the characteristics. The characteristics were influenced by Biggs et al. (2015)'s resilience principles, the attributes of general resilience in Walker and Salt (2012), and the list of resilience strategies in Appendix 1 in Sellberg (2013).

Table A3.1. Characteristics of a resilient system

\begin{tabular}{ll}
\hline \hline $\begin{array}{l}\text { Characteristics } \\
\text { of resilient } \\
\text { systems }\end{array}$ & Examples of questions for local planning \\
\hline Diversity & How can we maintain/increase biological diversity? \\
& $\begin{array}{l}\text { How can we maintain/increase human diversity? (Diversity of cultures, } \\
\text { perspectives and lifestyles) }\end{array}$ \\
& $\begin{array}{l}\text { How can we maintain/increase diversity of businesses? (Employers and } \\
\text { sectors) }\end{array}$
\end{tabular}

Overlap

(redundancy)

How can we meet important needs in many different ways, so that others will take over if one fails?

What measures could meet several different needs simultaneously?

Self-reliance How can we increase the degree of local self-sufficiency and, at the (modularity) same time, keep important exchanges with the surrounding world? How do we enable rapid local self-organization and decrease dependence of slow, hierarchical structures?

Slow variables How do we prepare for global changes, e.g. in the economy, climate and and feedbacks energy supply?

What are the gradual trends in our society and in nature that decreases the ability to deal with change? How can we turn them around? How can we strengthen the signals from those who see the effects to those who cause them and can change?

Learning, How do we build a local culture characterized by innovative thinking, participation, and ability to learning, and desire for experimentation?

innovate What attitudes promote this?

What meeting forms promote this?

Who need to be invited to participate?

Social-ecological How can we use experiences of how people have adapted to crises memory before?

How do we maintain knowledge of low-energy-intensive ways of meeting our needs, if that would be needed in the future? 
Buffers and reserves
Have any natural resources (or ecosystem services) decreased significantly lately? Which are plentiful/scarce? What buffers has the local community towards possible economic instabilities? 


\section{Appendix 4. Semistructured interviews}

Description of the semistructured interviews conducted with the partners, including interview guides.

We conducted semistructured interviews with the two collaborators from the partner organization, both before and after the workshops. The interview guides included topics and possible follow-up questions that were used as a checklist for the interview. An important part of ensuring high quality of the data was also to ask clarifying questions and ask for specific examples (e.g., Wagenaar 2011). Moreover, the second interview offered an opportunity to ask follow-up questions from the first interview, such as 9c. Questions are translated from Swedish. When analyzing the interviews, we followed the methods of Charmaz (2006) and performed both an initial and focused coding, since interviews display a rich source of data.

\section{Interview guide, before the first workshop}

1. Can you tell me how it came about that you wanted to start doing resilience workshops?

a. What happened at the Åre meeting (had discussed resilience there within the "LEADER learns for transition to sustainability"-project)?

b. What are your expectations with the workshops?

c. Have you worked with resilience within LEADER before?

d. How do you think it could impact the LEADER organization?

2. Can you tell me more about LEADER and the "LEADER learns for transition to sustainability"-project?

a. What are the organization's structure, size, aim, and funding?

b. Who are part of the organization?

c. Time frame for "LEADER learns for transition to sustainability"?

3. Can you tell med about your background in the Transition Movement?
a. In what way are you involved in the movement?
b. Your motivation?
c. Are you part of a local initiative?
d. What courses have you taken part in, and what books have you read?
e. Do you see yourself as a part of the movement?

4. Can you tell me where the different exercises in the workshop come from? Where did you learn them?

a. Go through the workshop agenda

b. In what way has the Resilience Assessment in Eskilstuna municipality (Sellberg et al. 2015) influenced?

c. Which parts origin from the Transition Movement?

d. What origins from other influences?

5. How do you see resilience and resilience theory?

a. What does the concept mean to you?

b. In what way do you think it is important?

c. What do you think are the most important contributions of resilience thinking?

6. Personal background (if not already mentioned): education, interests, earlier work, etc. 


\section{Interview guide, after the last workshop}

7. Did you learn anything from the process of planning and carrying out the resilience workshops, and in that case, what?

a. Did it turn out as you expected? Was there anything that made you surprised or disappointed?

b. What challenges has there been?

c. Will you have use of this in your future work? In what way?

8. In general, what do you think is the added value of combining the Resilience Assessment approach with the Transition Movement approach?

a. Are there any tensions/contradictions between them?

9. What has the Resilience Assessment approach contributed to the existing work with transition to sustainability within your organization?

a. Is the resilience perspective helping you to do what it is that you want to do in the organization? In what way?

b. Do you think the Resilience Assessment approach contributes with a more theoretical foundation, and in that case, does that provide any value?

c. (To one of the collaborators) In the last interview you talked about that you hoped the resilience perspective would decrease the clinch between rural development and sustainable development in the organization - how do you think that has turned out?

d. Do you think this project will have any impact on the strategy for the next 7 year period? In what way? Why/why not?

10. Can transition initiatives in other places benefit from learning more about resilience or doing resilience assessments? In what way? 


\section{Appendix 5. Focused codes from the case study analysis}

Here we provide descriptions and synthesized results for each of the focused codes in the inductive case study analysis, where we explored benefits and challenges of cross-fertilizing the Transition Movement and the Resilience Assessment approaches.

Inductive coding is an iterative process of describing, refining, and merging codes that significantly overlap (Wagenaar 2011). The codes were framed by our research question to identify benefits and challenges of cross-fertilization (Table 2). Several codes are related, and some overlap partially. In some of the codes benefits and challenges are mixed, e.g. in Resilience characteristics, but the order refers to when they appear in the results section. We refer to our collaborators from the partner organization as partner1 (P1) and partner2 (P2).

Table A5.1. Description and synthesized results for each of the focused codes

\begin{tabular}{ccc}
\hline \hline Code & Description & Synthesized results \\
\hline Reflections on commonalities and differences &
\end{tabular}

\section{Reflections on commonalities and differences}

1. Finding The common ground we

common ground experienced between the Resilience Assessment approach and the Transition Movement approach.

2. Acknowledging the different roles of research and movement
Both P1 and P2 said that they did not experience any contradictions between the two; rather the Transition Movement applies resilience thinking. Common ground was e.g. interest in the resilience concept and the aim to build resilience, as well as the complex systems perspective, which is also part of the core material of the Transition Movement. However, P1 emphasized that it is a pedagogical task to spread the understanding of resilience and complex systems within the movement.

Researchers and a social movement can do and say different things: e.g. a social movement can be clearer with saying what the problems and the solutions are, while an academic approach has to be more careful with e.g. clarifying underlying assumptions.

P1: You can't build a movement on only a resilience lens - the Transition Movement also includes values, e.g. fair share principle, and is more holistic, taking in more different influences.

The Resilience Assessment approach is more open to be used within different value contexts. 


\section{Benefits of cross-fertilization: Contributions of the Resilience Assessment approach}

\section{$3 . \quad$ Ways that the Resilience}

Operationalizing Assessment approach contributed

resilience to the workshop design and

helped the partners to

operationalize resilience.
4. Reaching new groups

\section{Bridging divide/bypassing clinch}

A benefit that $\mathrm{P} 1$ and $\mathrm{P} 2$ experienced with the Resilience Assessment approach, in this case that they could reach new target groups.

A benefit that $\mathrm{P} 1$ and $\mathrm{P} 2$ experienced with the Resilience Assessment approach, in this case that they could bridge a divide in
- Using the structure of the Resilience Assessment approach: going through the steps of defining "resilience of what" and "to what" gave P1 and P2 the overall structure for the workshop (Appendix 1).

- "Characteristics of resilient systems" (Appendix 2): During the project we clarified, translated and wrote descriptions of them that would be comprehensible for the workshop participants. This was an important part of learning how to communicate resilience and operationalize the concept. The characteristics are open enough to be applied to different dimensions, e.g. also social and economic, and to include both strengths and weaknesses. They also were helpful in arguing for why diversity is important (P1). It was difficult to find existing quantitative data relating to the workshop output for the different characteristics, e.g. ecological and cultural diversity and economic modularity.

- Including a historical perspective on the focal system: The partners integrated the historical perspective into an adapted version of the "Web of resilience"-exercise. The quality of the historical input at the workshops depended on the participants and their local historical knowledge.

The Resilience Assessment approach offered a possibility to reach new target groups that were previously closed for P1 and P2, since resilience is a new concept and you can reframe sustainability. In this case, the new target groups were "ordinary" people living in small, rural communities, and people who are prejudiced against sustainability, who have been difficult to reach in the past with projects related to transition to sustainability.

P2's original aspiration with the resilience workshops was to bridge the divide and get past the clinch in the organization between people promoting transition to sustainability and caring for environmental issues vs. those promoting rural development, usually in the form of economic development and assuming unlimited 
their organization.

\section{Reframing}

sustainability

Underlying possibilities and challenges with using the concept of resilience instead of sustainability, especially identified by $\mathrm{P} 2$.

7. Including local and global issues

A benefit that $\mathrm{P} 1$ and $\mathrm{P} 2$ experienced with the Resilience Assessment approach, in this case that they could address both local and global issues. economic growth. During the collaboration project he saw enough examples of this to continue to believe in this possibility. The Resilience Assessment approach helps e.g. because of reframing and inclusion of both local and global issues of concern (see below).

Possibilities: talking about sustainability (or about things that will lead to sustainability) using resilience and relating to vulnerability, both in general and of communities in particular, is a way to make sustainability and more egoistic concerns go hand in hand. This helps with Reaching new groups and Bridging the divide in the organization, and is something new compared to how they have worked with the Transition Movement approach: "My experience of the Transition Movement is not so much that it is about sensitivity and vulnerability, but more about transitioning for the sake of the climate, that is a lot for someone else's sake, for your children and grandchildren's sake" (P2).

Challenge: need to have a long time perspective and big geographical scale for resilience to overlap with sustainability. This framing emphasizes sustainability for the sake of yourself, your family, or your community, which P2 identifies as a potential risk. It is challenging to communicate the need for coordination across scales and between different places, and e.g. mitigation of climate change, while still appealing to people's more egoistic values. However, P1 sees resilience as positive, since it is less static compared to many metaphors for sustainability.

The Resilience Assessment approach had an analytical frame and a workshop design that was more open to a broad range of issues and included both local and global issues. At each of the workshops both global and local issues were raised, even if the proportions varied depending on the participants.

With the Transition Movement approach, they had focused more on global issues, e.g. mitigating climate change, and peak oil, but the Resilience Assessment approach gave a new focus on the vulnerability of local communities and a possibility to include 


\section{Highlighting strengths}

9. Using new concept

10.

Problematizing global economy
A benefit that $\mathrm{P} 1$ and $\mathrm{P} 2$ experienced with the Resilience Assessment approach, in this case that it the highlighted strengths of rural communities.

Challenges and opportunities of using a new concept - resilience.

$\mathrm{A}$ benefit that $\mathrm{P} 1$ and $\mathrm{P} 2$ experienced from the collaboration project, in this case that it helped them to problematize the global economy. both local (e.g. relating to own community and landscape) and global concerns. P1 saw this as a way to facilitate the pedagogical task of making global issues comprehensible to a local context.

Many participants mentioned that the workshop highlighted the local-global connections, even though some also experienced that either the global connection got lost, or that some of the resilience characteristics were to abstract and global to connect to the local.

It was useful for P1 and P2 that the Resilience Assessment approach also highlighted strengths, and not only weaknesses, of small, rural communities. This added something new compared to their existing work with transition to sustainability. E.g. participants in the workshops used the folder with characteristics of resilient systems to discuss both strengths and weaknesses of their communities and landscapes.

People are less prejudiced about resilience compared to sustainability, which makes it easier to reach new target groups. The challenge relates to the pedagogical task of teaching a new concept, which often is perceived as complicated and requires time for learning.

Both $\mathrm{P} 1$ and $\mathrm{P} 2$ were strengthened by the project in problematizing the globalized economy. For example by using the "characteristics of a resilient system" to point how the global economic system lacked resilience. P1 also saw the global economy as a common root cause to both environmental problems and rural development problems, which could help bridging the two (see 5. Bridging divide/bypassing clinch).

\section{Benefits of cross-fertilization: contributions of the Transition Movement approach}

11. Using

pedagogical
Participant observations of

pedagogical exercises and that
We used different playful and pedagogical exercises in the workshops to facilitate understanding of resilience and complex systems. Most of the exercises came from 
exercises

12.

Acknowledging

emotions

13. Promoting

transition were part of the workshop design and were new to the Resilience Assessment approach.

Participant observations of how P1 and P2 acknowledged participants' emotions in the workshops.

Participant observations of how $\mathrm{P} 1$ and $\mathrm{P} 2$ promoted transition to sustainability during the collaboration project. the Transition Movement, even if they had been adapted a bit, e.g. the "Web of Resilience"-exercise (Hopkins 2008:60). Some were completely new and developed by P1 and/or P2. The exercises were new to the Resilience Assessment approach. Usually the exercises encouraged a discussion afterwards about the concepts or the situation in the community. They were appreciated by many of the participants, but also required time.

After introducing global sustainability challenges $\mathrm{P} 1$ gave space for participants to express their emotions. Awareness in P1 and P2 of how change and global crises awakens psychological defenses in people, and that it is important to acknowledge these emotions when they arise. When a participant in one of the workshops expressed feeling threatened, $\mathrm{P} 1$ and $\mathrm{P} 2$ recognized this and facilitated the discussion.

P1 and P2 promoted transition to sustainability, both of individual's worldviews and of society/communities, and a global sustainability perspective within their organization. They also used the Resilience Assessment approach as a way to promote transition. For example:

1) Focusing "resilience of what" on basic needs opened up for changing the current way of providing for those needs.

2) Introducing global sustainability challenges before the "resilience to what" motivated the need for transition.

Transition to sustainability is also part of the context, since the project is part of "Leader learns for transition to sustainability" and there is ongoing work within their organization related to transition to sustainability.

Focus was on resilience of local communities, and using basic human needs as a starting point, as well as things contributing to life quality.

\section{Defin
what"}

How we asked the question of what it is that should be resilient, how it was framed, in the workshops. 


\section{Challenges of cross-fertilization and of operationalizing resilience}

\author{
15. The \\ pedagogical task \\ Recognition of the pedagogical \\ task of facilitating resilience \\ workshops.
}

\section{The learning}

process

\section{Openness in participatory process}

18. Loosing the ecological dimension?
When P1 and P2 talk implicitly about an underlying learning process in each individual, both in themselves and in the participants.

Participant observations of challenges relating to the openness of the participatory process.

Tracking through the project if the ecological dimension, as well as the idea of social-ecological interactions, was present.
Both $\mathrm{P} 1$ and $\mathrm{P} 2$ recognized that we took on a pedagogical task in communicating abstract and theoretical concepts, and global issues to local people in a way that makes it relevant for them in their context, and in a short amount of time. How to give a sense of resilience thinking, both the concept and the worldview around it. In the workshops, there were both examples of when we succeeded and not in this task. It appeared to be very individual, how easy it was for the participants to grasp and appreciate the way of thinking.

It is a learning process to grasp the global sustainability perspective, and the abstract concepts, like resilience, when you're operating in a very local context. The learning process requires motivation and interest, and time. It is not easy, and only information is not enough, especially when the new ideas conflict with existing worldviews. Understanding resilience thinking requires e.g. examples, time for reflection and emotions, pedagogical exercises, and connections to your own context and own mental models. It is a challenge to get enough time and to get the same participants involved for a longer period of time.

There are multiple challenges here, but only most relevant for the combination of the two approaches is the challenge of promoting transition to sustainability, while at the same time creating a participatory process that was open to the participants' issues of concern and value systems. This relates to combining the different roles of research and a social movement in fruitful ways.

It was a part of the "Web of Resilience"-exercise, the context cards, and the folder (see Appendix 1 and 2). It was also part of the results from each workshop, even though it depended on the people in the room - both the facilitator and the participants, and what issues they brought up. 